\title{
Histological and virological findings in severe meningoencephalitis associated with border disease virus in Alpine chamois (Rupicapra rupicapra rupicapra) in Aosta Valley, Italy
}

\author{
Massimo Giangaspero*, Lorenzo Domenis, Serena Robetto and Riccardo Orusa \\ Centro di Referenza Nazionale per le Malattie degli Animali Selvatici (CeRMAS), Istituto Zooprofilattico \\ Sperimentale del Piemonte, Liguria e Valle d'Aosta, Quart, Italy
}

\begin{abstract}
In 2015, a young female Alpine chamois (Rupicapra rupicapra rupicapra), originated from the Aosta Valley Region, Northernwestern Italy, was conferred to the National Reference Centre for Wild Animal Diseases for pathologic examinations. Histological analysis revealed a severe meningoencephalitis characterized by lymphocytic and plasmacellular infiltration, gliosis, perivascular cuffs, and leptomeningitis at the level of brain and brain stem. Laboratory investigations included polymerase chain reaction, sequencing and characterization by phylogenetic analysis, and evaluation of the internal ribosome entry site secondary structure in the 5' untranslated region. These tests identified the pathological agent as border disease virus, a known health risk in domestic small ruminants. Genetic characteristics of the isolated strains, closely related to ovine and caprine strain sequences from neighboring regions of Piedmont, France, and Switzerland, suggested geographic segregation and micro-evolutive steps within the species. Keywords: Alpine chamois, Border disease virus, Meningoencephalitis, Pestivirus, Rupicapra rupicapra rupicapra.
\end{abstract}

\section{Introduction}

In the northwestern Italian region of Aosta Valley, a regular and wide monitoring program is operational under the guidance and supervision of the National Reference Centre for Wild Animal Diseases (CeRMAS). In the framework of this activity, carcasses of wild ruminants are regularly conferred to CeRMAS for gross pathologic, histologic, bacteriologic, and virologic examinations, as part of the health surveillance of wild animals.

On July 8, 2015, a young Alpine chamois (Rupicapra rupicapra rupicapra) was submitted to CeRMAS. The animal was found near a road in the vicinity of the municipality of Antey Saint Andrè in Valtournenche, an alpine area with an altitude of about 1,000 $\mathrm{m}$ above sea level, characterized by the concomitant presence of cattle, sheep, goats farms, and wild ruminant ungulates (ibex, chamois, and roe deer). Collected by personnel of the Forest Rangers and transported to the wild fauna rescue centre of Quart, the animal, showing depression, difficulty of movement, and loss of fear for humans, was admitted for suspected heat exhaustion and subsequently euthanized due to its critical condition. Considering that the Alpine chamois population mating season occurs between the beginning of November and mid-December with subsequent births from mid-May until mid-June, the age of the animal was estimated between 1 and 2 months.

In line with the overall presentation of the case, a new border disease virus (BDV) was detected in the spleen and lungs of the animal and proposed as BDV genotype 8 (Caruso et al., 2017). Despite the presence of a severe meningoencephalitis, testing was inconclusive at the brain level. In order to confirm the presence of a new cluster in the species and verify a link between BDV and the central nervous system (CNS) lesions, a further investigation was carried out in collaboration with the Office International des Epizooties reference centre for classical swine fever (CSF) and bovine viral diarrhea viruses (BVDV) at the Animal and Plant Health Agency (APHA), UK. The results not only allow us to corroborate the previous results but also allow us to conclude that the meningoencephalitis was likely associated with the BDV infection.

\section{Case Details}

\section{Post-mortem examination}

After recording morpho-biometric data (age, sex, and weight), gross pathology lesions were determined at post-mortem examination according to a standard protocol. The organs with the most significant lesions were subjected to histological, bacteriological, parasitological, and virological procedures to complement the patho-morphologic investigations.

Brain, brain stem, and lungs were fixed in 10\% neutral buffered formalin, embedded in paraffin wax, and cut into $4 \mu \mathrm{m}$ thickness sections using a microtome. The sections were placed on slides, deparaffinized in Bioclear (Gene Linx International, Inc., Dublin, OH), rehydrated in decreasing gradations of alcohol, washed, 
and stained with hematoxylin and eosin followed by dehydration in increasing concentrations of alcohol, cleared in Bioclear (Gene Linx International), mounted with a coverslip using Eukitt mounting medium (Kindler GmbH, Freiburg, Germany), and analyzed under an Olympus BX 60 light microscope (Olympus Europa GmbH, Hamburg, Germany).

\section{Bacteriological and parasitological tests}

Bacteriological examination was performed by Blood and MacConkey Agar over $48 \mathrm{~h}$ at $37^{\circ} \mathrm{C}$ in an aerobic atmosphere. Colonies of interest, isolated from the lung, were characterized by morphology, catalase and oxidase test, and Gram staining and typing by APINE Biomerieux biochemical tests. A parasitological examination has been carried out from the intestine by fecal floatation by $100 \%$ zinc sulphate solution.

\section{RT-PCR and DNA sequencing}

Viral RNA was extracted from fixed brain tissue samples using the RNeasy FFPE Qiagen kit according to the manufacturer's protocol. All samples were tested using a short target real-time RT-PCR capable of differentiating between BDV and BVDV (La Rocca and Sandvik, 2009). The 5'-UTR was amplified by reverse transcription using the Superscript ${ }^{\circledR}$ III reverse transcription kit (Invitrogen, UK) as per the manufacturer's protocol, followed by PCR with primers V324 and V326 (Vilcek et al., 1994). Sequencing of the purified amplicons on both strands was performed applying the Big Dye cycle sequencing technology and using the automated ABI3730 DNA sequencer.

\section{Genetic typing}

A phylogenetic tree based on the 5'-UTR was constructed with Clustal X (Chenna et al., 2003) using the neighbor-joining method (Saitou and Nei, 1987) and visualization with Newick tree format option in Mega (version 7.0.26) (Kumar et al., 2016).

Qualitative and quantitative evaluation of genomic sequence divergence, in terms of palindromic nucleotide base pairings variations, has been applied through the consideration of relevant secondary structure regions in the 5'-UTR of the viral RNA, the three variable regions, V1, V2, and V3 genomic sequences, according to the genotyping based on the palindromic nucleotide substitution (PNS) method (Giangaspero and Harasawa, 2007). Internal ribosome entry site (IRES) types were identified according to base-pair (bp) combinations at the level of low-variable positions and ranked with alphabetic nomenclature according to increasing divergence in the species. The classification among BDV strains according to the PNS analysis based on changes in the secondary structure was compared with those based on the primary structure of the 5'-UTR performed through sequence alignment and construction of phylogenetic trees.

\section{Gross pathology}

At necropsy, the young female Alpine chamois (CeRMAS register 58987/2015) showed apparent good general condition. Gross lesions were evident at the head of the animal, characterized by a temporal-parietal subcutaneous hematoma at the right side and a related left sub-meningeal hemorrhage. In addition, the animal suffered from pneumonia with consolidated apical lobes, intestinal meteorism associated with segmental catarrhal enteritis, hepatic discoloration, and softening of renal tissue.

\section{Histopathology}

Microscopy revealed a severe and diffuse nonsuppurative lymphohistiocytic meningoencephalitis (Fig. 1A-D). Associated histological lesions observed at the level of CNS tissues were focal cortical hemorrhage (red cells in brain parenchyma), mild perivascular mononuclear cuffs, gliosis, neutrophilic aggregates, and leptomeningitis.

Lungs presented suppurative broncho-pneumonia characterized by bronco-alveolar spaces filled with neutrophils, foamy macrophages, fluid, and occasionally fibrin aggregates, interlobular edema, and hyperemia. No lesions were evident at the level of kidneys and liver.

Specimens of formalin-fixed and paraffin-embedded tissues submitted to IHC staining were all negative for pestiviruses (data not shown).

\section{Bacteriological and parasitological examination}

Additional tests for the screening of pathogens, other than pestiviruses, showed the presence of bacteria in the lungs. Translucent colonies, grown on Blood

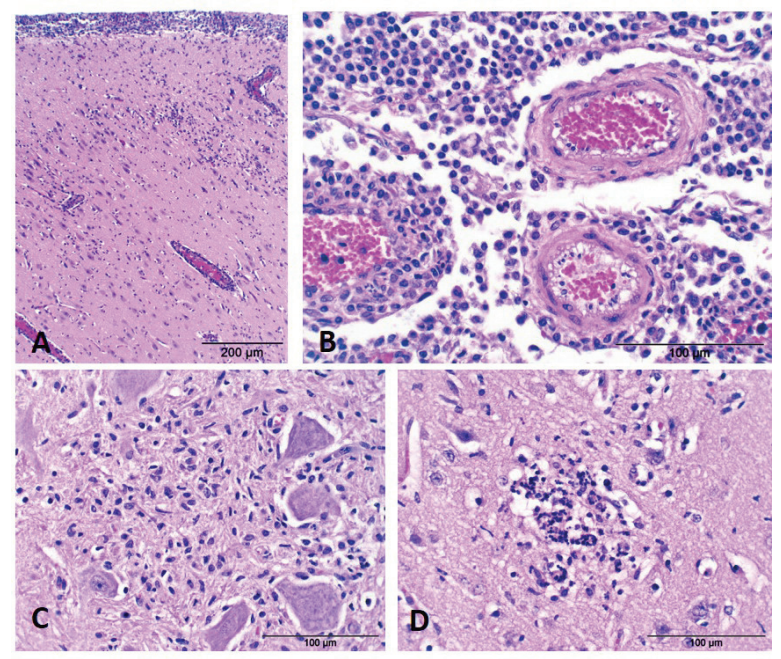

Fig. 1. Histological lesion associated with Pestivirus strains Chamois-VdA-2 and Chamois-VdA-3. Detail of severe meningoencephalitis: (A) Brain (occipital lobe): severe and diffuse non-suppurative lymphohistiocytic meningoencephalitis characterized by meningeal thickening due to monocytic infiltration, perivascular cuffing, and gliosis. (B) Meninges (parietal lobe): severe flogosis consisting of lymphocytes, macrophages, and some neutrophils. (C) Brain (mesencephalon): gliosis with the focal proliferation of glial cells between neurons associated with lymphocytes and monocytes. (D) Brain (occipital lobe): focal infiltration of neutrophils in the white matter of occipital lobe. 
Agar, formed by capsulated Gram-negative coccobacilli, positive at catalase and oxidase tests, were characterized by biochemical identification as Mannheimia haemolytica. No pathogenic bacteria have been found in kidneys, liver, and intestine. The parasitological examination revealed a high level of infestation by gastro-intestinal strongili and coccidia.

Molecular detection and analysis of BDV in brain sample

Applying the BDV specific PCR (Strong et al., 2010), two strains of BDV were detected in the two areas of the Alpine chamois brain (mesencephalon and occipital cortex), as well as in the spinal cord and lungs. The 5'-UTR sequences of isolates Chamois-VdA-2 and Chamois-VdA-3 have been deposited in the DDBL/ EMBL/GenBank DNA database under accession numbers MG725337 and MG725338, respectively.

Strains Chamois-VdA-2 and Chamois-VdA-3 belonged to $\mathrm{BDV}$ species, clustered as genotype BDV-c, subgenotype 3. The 5'-UTR sequences were very similar to the isolate Italy-58987 (Caruso et al., 2017), detected in the spleen of the same animal. Based on secondary structure characterization, the main difference was evident at the level of the IRES Domain D (Deng and Brock, 1993), showing a longer V3 locus when compared to the secondary sequence of isolate Italy-58987. According to the sequencing chromatogram of the 5'UTR from the brain sample of strains Chamois-VdA-2 and Chamois-VdA-3, thymine and guanine nucleotides have been obtained in position 169, respectively (Fig. 2), suggesting a quasispecies phenomenon. A phylogenetic tree based on the 5'-UTR is presented in Figure 3.

Both the strains resulted related to strains $\mathrm{CH}-\mathrm{BD} 3$ and CH-BD4 (Peterhans et al., 2010; Casaubon et al., 2012), Italy-103761 (Peletto et al., 2016), reported from Swiss and Italian small ruminants, and clustered as subgenotypes BDV-c1 and BDV-c3. They were also related to the French ovine strains, reported from the region of Provence Alpes Côte d'Azur (PACA) (Dubois et al., 2008) and to the strain Rupi-05 (Martin et al., 2015), isolated in an Alpine chamois in the French Alps, all included in the subgenotype BDV-c2 (Table 1). Among BDV-c2 strains, Rupi-05 was the closest to BDV-c1 and BDV-c3.

Comparison of the classification among BDV strains according to the PNS analysis based on changes in the secondary structure with those based on the primary structure of the 5'-UTR performed through sequence alignment and construction of phylogenetic trees showed some differences. Apart from different numerical and alphabetic nomenclature applied for linear sequence analysis and for PNS method, respectively, discrepancies have been observed in relation to the allocation of strains into genotypes and subgenotypes. In particular, strains reported by PNS as

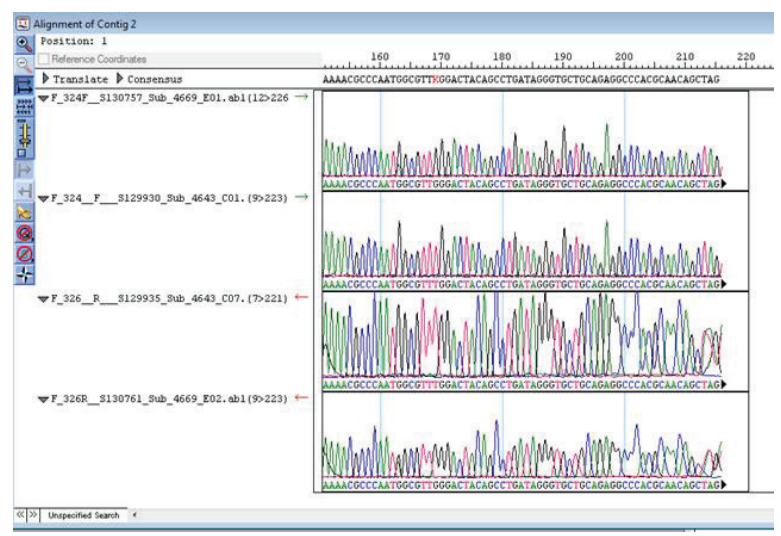

Fig. 2. Sequencing chromatogram of the 5'-UTR from the brain sample of strains Chamois-VdA-2 and ChamoisVdA-3. Both thymine and guanine nucleotides have been obtained in position 169 .

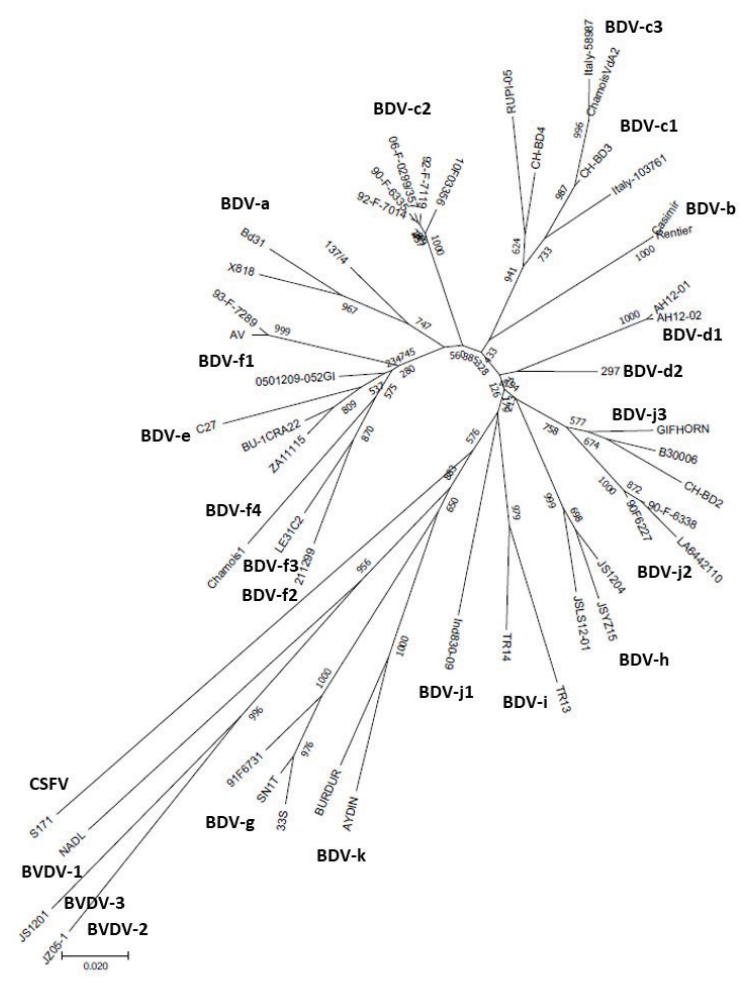

Fig. 3. Phylogenetic tree based on the 5'-UTR genomic region comparison, suggesting a taxonomic position of the chamois isolates Chamois-VdA-2 and Chamois-VdA-3 (accession numbers MG725337 and MG725338) in the BDV cluster. Comparison with nucleotide sequences of the reference BDV strains of bovid ruminants and suids. Distances were computed with Clustal X using the neighbor-joining method. Numbers at the relevant branches refer to bootstrap values of 1,000 replications. Scale bar indicates 10 nucleotide substitutions per 100 nucleotides. 
Table 1. BDV species genotype $\mathrm{c}$ strains $(n$ 17) evaluated according to the palindromic nucleotide substitution (PNS) method at the 5' untranslated region of RNA. Genotype nomenclature is indicated according to PNS and primary sequence analysis (PSA).

\begin{tabular}{|c|c|c|c|c|c|c|c|}
\hline \multicolumn{2}{|c|}{ Genotype } & \multirow{2}{*}{ Strain } & \multirow{2}{*}{ Origin } & \multirow{2}{*}{ Country } & \multirow{2}{*}{$\begin{array}{c}\text { Collection } \\
\text { date }\end{array}$} & \multirow{2}{*}{ Accession } & \multirow{2}{*}{ Reference } \\
\hline PNS & PSA & & & & & & \\
\hline c1.1 & Switzerland & CH-BD3 & Sheep & Switzerland & 2006 & JQ994199 & $\begin{array}{l}\text { Stalder et al. } \\
\text { (unpublished) }\end{array}$ \\
\hline c1.1 & Switzerland & CH-BD4 & Sheep & Switzerland & 2006 & JQ994200 & $\begin{array}{l}\text { Stalder et al., } \\
\text { unpublished }\end{array}$ \\
\hline $\mathrm{c} 1.2$ & 8 & Italy-103761 & Goat & Italy & 2014 & КТ072634 & $\begin{array}{l}\text { Peletto et al. } \\
(2016)\end{array}$ \\
\hline c2 & & $06-\mathrm{F}-0299 / 357$ & Sheep & France: PACA & 2006 & EF694000 & $\begin{array}{l}\text { Dubois et al. } \\
(2008)\end{array}$ \\
\hline c2 & 6 & $06-F-0299 / 369$ & Sheep & France: PACA & 2006 & EF694001 & $\begin{array}{l}\text { Dubois et al. } \\
(2008)\end{array}$ \\
\hline $\mathrm{c} 2$ & 6 & $06-F-0299 / 420$ & Sheep & France: PACA & 2006 & EF694002 & $\begin{array}{l}\text { Dubois et al. } \\
\text { (2008) }\end{array}$ \\
\hline c2 & 6 & 06-F-0299/477 & Sheep & France: PACA & 2006 & EF694003 & $\begin{array}{l}\text { Dubois et al. } \\
(2008)\end{array}$ \\
\hline c2 & 6 & $10 \mathrm{~F} 03356$ & Sheep & France & 2010 & KC859384 & $\begin{array}{l}\text { Martin et al. } \\
(2015)\end{array}$ \\
\hline c2 & 6 & $90-F-6335$ & Sheep & France: PACA & 1990 & EF693990 & $\begin{array}{l}\text { Dubois et al. } \\
(2008)\end{array}$ \\
\hline c2 & 6 & 91-F-7014 & Sheep & France: PACA & 1991 & EF693993 & $\begin{array}{l}\text { Dubois et al. } \\
(2008)\end{array}$ \\
\hline $\mathrm{c} 2$ & & $92-F-7119$ & Sheep & France: PACA & 1992 & EF693994 & $\begin{array}{l}\text { Dubois et al. } \\
(2008)\end{array}$ \\
\hline c2 & 6 & 94-F-7446/1 & Sheep & France: PACA & 1994 & EF693996 & $\begin{array}{l}\text { Dubois et al. } \\
(2008)\end{array}$ \\
\hline $\mathrm{c} 2$ & & $94-F-7446 / 2$ & Sheep & France: PACA & 1994 & EF693997 & $\begin{array}{l}\text { Dubois et al. } \\
(2008)\end{array}$ \\
\hline c2 & 6 & RUPI-05 & $\begin{array}{l}\text { Alpine } \\
\text { chamois }\end{array}$ & France: PACA & 2011 & KC859383 & $\begin{array}{l}\text { Martin et al. } \\
(2015)\end{array}$ \\
\hline c3 & 8 & Italy-58987 & $\begin{array}{l}\text { Alpine } \\
\text { chamois }\end{array}$ & Italy & 2015 & KX573913 & $\begin{array}{l}\text { Caruso et al. } \\
(2017)\end{array}$ \\
\hline c3 & & Chamois-VdA-2 & $\begin{array}{l}\text { Alpine } \\
\text { chamois }\end{array}$ & Italy & 2015 & MG725337 & Present work \\
\hline c3 & & Chamois-VdA-3 & $\begin{array}{l}\text { Alpine } \\
\text { chamois }\end{array}$ & Italy & 2015 & MG725338 & Present work \\
\hline
\end{tabular}

PACA: Provence Alpes Côte d'Azur; Host: Alpine chamois (Rupicapra rupicapra rupicapra); Goat (Capra hircus); Sheep (Ovis aries).

subgenotypes BDV-c1 and BDV-c3 corresponded to BDV Switzerland (CH-BD3 and $\mathrm{CH}-\mathrm{BD})$ (Peterhans et al., 2010; Casaubon et al., 2012) and BDV-8 (Italy-58987 and Italy-103761) (Peletto et al., 2016; Caruso et al., 2017). Similarly, the French strains defined as genotype 6 were genetically related to BDV-c1 and BDV-c3. A schematic representation of the geographic distribution of genotype BDV-c and related sub genotype variants circulating in restricted areas is presented in Figure 4.

\section{Discussion}

The anamnestic report, gross pathology, and histological lesions suggested that the animal was exposed to a severe trauma (head wounds and brain hemorrhage), possibly a car accident, given the location where it was rescued, and in line with the reduced sensorial capacity caused by CNS lesions. However, car accidents occur easily when wild animals are affected by neurological disorders, including infections which change the natural behaviour and can cause a loss of shyness. 


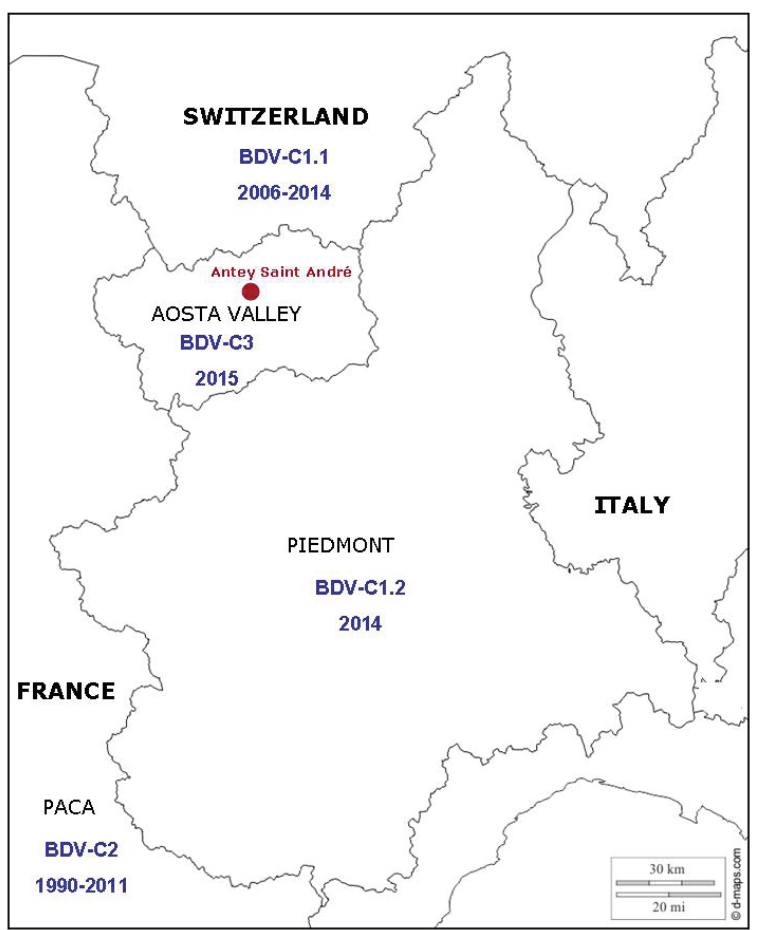

Fig. 4. Schematic representation of the geographic distribution of genotype BDV-c and related variants. The location where a young female Alpine chamois has been rescued by Forest Rangers and conferred to CeRMAS on July 8, 2015 (CeRMAS register 58987/2015) is indicated by a red point. PACA: Provence Alpes Côte d'Azur.

The features of meningoencephalitis, with a prevalent non-suppurative response, strongly suggested a viral infection (Storts, 1995). However, the presence of a virus in the brain had not been confirmed before (Caruso et al., 2017). BDV was detected here and may thus be associated with severe meningoencephalitis, considering that some of the microscopical lesions (such as cortical hemorrhages) may otherwise be the result of the trauma.

CNS tropism and the adverse impact of BDV during fetal development are well known in domestic small ruminants. BDV is responsible for congenital viral infection affecting sheep (Ovis aries), with abortions, barren ewes, stillbirths, and small weak lambs, which can show tremors, abnormal body conformation, and abnormal birth coat. The disease in goats (Capra aegagrus hircus) is rare and characterized by abortions (Nettleton et al., 1998). It is not known whether these conditions also occur in free-ranging chamois (Rupicapra rupicapra), considering the difficulty to study abortions and post-natal diseases in wildlife. However, despite CNS lesions are observable in chamois, the suspected etiopathological role of Pestivirus is not confirmed. In our knowledge, only one strain (AND-3, accession number HE615085) has been reported from the host brain of a Pyrenean chamois
(Rupicapra pyrenaica) in Andorra in 2009. Clinical signs, gross and microscopical lesions observed in the Italian chamois here, were similar to those described in natural and experimental infections in Pyrenean chamois (Marco et al., 2007; Martin et al., 2013).

Broncho-pneumonia is frequently found in chamois (Citterio et al., 2003), but in our case, it may have been promoted as secondary infection by immunosuppressive effects conferred by and attributed to BDV infection: we observed the typical features of suppurative bronchopneumonia and isolated Mannhemia haemolytica.

Characteristic genetic cluster of BDV species was restricted in Italy related to other isolates from France and Switzerland. Secondary structure alignment and computing of divergence values by comparison with other Pestivirus sequences suggested relatedness with different strains defined as genotypes BDV-6 (Dubois et al., 2008; Martin et al., 2015), BDV-8 (Caruso et al., 2017), and BDV Switzerland (Peterhans et al., 2010; Casaubon et al., 2012). In this genetic group, PNS BDV-c clustering was related to geographic origin (Switzerland C1.1, France C.2, and Italy C1.2/C.3) and host (domestic C1.1/C1.2/C.2 or wild C.2/C.3). Strains defined as genotypes 6,8 , or BDV Switzerland have not been compared to each other for taxonomical definition by the authors. Therefore, it was not possible to consider sequence similarities that in the present study resulted according to secondary structure analysis and construction of a phylogenetic tree. Thus, this might be a further case of taxonomical clustering without complete consideration of deposited sequences and published different interpretations and nomenclatures provided by other authors.

Genetic relation among strains isolated in France, Italy, and Switzerland, belonging to genotype BDV-c, suggested geographic segregation and evolutionary dynamic of a specific subgroup in the BDV species, related also to exchanges between domestic and wild ruminants (Fig. 3). All these strains resulted in circulating in three restricted neighboring regions. In each region, strains showed distinctive genomic characteristic. Most of the sequences originated from sheep, chronologically, first reported between 1990 and 1994, all from the French southeastern region PACA. About a decade later, other closely related sequences have been reported from ovine in Switzerland, showing also recent circulation in cattle (Frei et al., 2014). Then, in 2014, the virus was detected in small ruminants from the Italian northwestern region of Piedmont. In the following year, Alpine chamois from Aosta valley has been shown to harbor a similar virus. Alpine chamois from France was also affected by a related virus earlier in 2011. Since virologic monitoring has been regularly performed, it is likely that these virus types were not circulating previously. A common geographic trait was the Alpine mountain chain, a natural barrier 
separating the respective areas. Alps are the habitat of the Alpine chamois. This wild species may enter in contact with domestic small ruminants through the use of pastures located at a higher altitude during seasonal transhumance or by occasional contact in the surrounding of backyard farms in Alpine valleys. This aspect may indicate the potential for spillover from farm animals in wild fauna, rather than representing a natural reservoir, but not excluding the adaptation in the species and evolutionary dynamics of the virus in the new host species. The two sequences from the Alpine chamois from France and Italy were different and related to isolates from domestic animals of their respective origin.

Small ruminant stocks farmed in the Aosta Valley region account for 2,000 sheep and 5,000 goats Istituto Zooprofilattico Sperimentale del Piemonte, Liguria e Valle d'Aosta, 2008 while the population of wild ungulates is estimated at about 23,000 animals (CeRMAS, 2012; detailed data available under request), composed primarily by wild boar (Sus scrofa), ibex (Capra ibex ibex), roe deer (Capreolus capreolus), deer (Cervus elaphus), and chamois (Rupicapra rupicapra rupicapra). Considering the semi-rural farming environment where the animal has been found, this supports the likely intercurrent contacts of the chamois population with domestic animals.

No specific information is available on potential wild reservoir species for BDV (EFSA et al., 2017). However, wild fauna seems to be subjected to spillover from domestic ruminants. Strains isolated from Alpine chamois in Italy and France and from Pyrenean chamois in Spain, Andorra, and France suggested a domestic small ruminants origin (ANSES, 2017), for example, an ovine origin of the occurrence of BDV-4 in Pyrenean chamois (Luzzago et al., 2016; ANSES, 2017). Similar cases have been reported previously in the same region involving caseous lymphadenitis caused by Corynebacterium pseudotuberculosis in Alpine chamois (Domenis et al., 2018), roe deer affected by Mycobacterium bovis (Balseiro et al., 2009; Domenis et al., 2010), or ibex affected by Mycoplasma mycoides subsp. capri LC serovar (MmcLC), causative agent of infectious agalactia (Giangaspero et al., 2010). Such health risks are different from those frequent in wild fauna as $M$. conjunctivae agent of infectious keratoconjunctivitis, a highly contagious ocular disease, reported in wild animals in the Alpine regions of Italy (Grattarola et al., 1999), less related to spillover from domestic animals.

Monitoring and improved management of wild fauna are important to protect the unique and precious Alpine ecosystem in Europe. In the present study, according to secondary structure analysis, the BDV species resulted heterogeneous. Sequence characteristics of the genotype BDV-c genomic cluster of the BDV species, circulating in regions of France, Italy, and Switzerland, suggested geographic segregation. Determination of BDV species heterogeneity is important for diagnostic efficiency and prophylactic purposes, taking into account the adverse health and economic impact on small ruminant farming and potential negative impact on wild fauna.

\section{Acknowledgments}

The authors would like to thank Prof. F. Steinbach and Dr. R. Strong, Mammalian Virology Group, Virology Department, Animal and Plant Health Agency (APHA), United Kingdom, for the help in diagnostic testing and valuable discussion on the manuscript.

\section{References}

Agence nationale de sécurité sanitaire de l'alimentation, de l'environnement et du travail (ANSES). 2017. Pestivirose dans les Pyrénées. Saisine no 2015SA-0194. Rapport d'expertise collective. ANSES, Maisons-Alfort, France, July 2017.

Balseiro, A., Oleaga, A., Orusa, R., Robetto, S., Zoppi, S., Dondo, M., Goria, M., Gortàzar, C., Garcìa Marìn, J.F. and Domenis, L. 2009. Tuberculosis in roe deer from Spain and Italy. Vet. Rec. 164, 468470.

Caruso, C., Peletto, S., Cerutti, F., Modesto, P., Robetto, S., Domenis, L., Masoero, L. and Acutis, P.L. 2017. Evidence of circulation of the novel border disease virus genotype 8 in chamois. Arch. Virol. 162(2), 511-515.

Casaubon, J., Vogt, H.R., Stalder, H., Hug, C. and RyserDegiorgis, M.P. 2012. Bovine viral diarrhea virus in free-ranging wild ruminants in Switzerland: low prevalence of infection despite regular interactions with domestic livestock. BMC Vet. Res. 8, 204.

Chenna, R., Sugawara, H., Koike, T., Lopez, R., Gibson, T.J., Higgins, D.G. and Thompson, J.D. 2003. Multiple sequence alignment with the Clustal series of programs. Nucl. Acids Res. 31, 3497-3500.

Citterio, C.V., Luzzago, C., Sala, M., Sironi, G., Gatti, P., Gaffuri A. and Lanfranchi, P. 2003. Serological study of a population of alpine chamois (Rupicapra rupicapra) affected by an outbreak of respiratory disease. Vet. Rec. 153, 592-596.

Deng, R. and Brock, K.V. 1993. 5' and 3' untranslated regions of pestivirus genome: primary and secondary structure analyses. Nucl. Acids Res. 21, 1949-1957.

Domenis, L., Robetto, S., Pepe, E., Spedicato, R., Marchisio, F., Demurtas, G. and Orusa, R. 2010. Diagnostic approach to wild animals diseases described through a reference case report of tuberculosis in roe deer (Capreolus capreolus). In Proceedings of the 1st Congress of European Association of Veterinary Laboratory Diagnosticians (EAVLD), Lelystad, The Netherlands, 15-17 September 2010, pp: P-1-21. 
Domenis, L., Spedicato, R., Pepe, E., Orusa, R. and Robetto, S. 2018. Caseous lymphadenitis caused by Corynebacterium pseudotuberculosis in alpine chamois (Rupicapra r. rupicapra): a review of 98 cases. J. Comp. Path. 161, 11-19.

Dubois, E., Russo, P., Prigent, M. and Thiéry, R. 2008. Genetic characterization of ovine pestiviruses isolated in France, between 1985 and 2006. Vet. Microbiol. 130, 69-79.

European Food Safety Agency (EFSA); AHAW Panel (EFSA Panel on Animal Health and Welfare); More, S., Bøtner, A., Butterworth, A., Calistri, P., Depner, K., Edwards, S., Garin-Bastuji, B., Good, M., Gortázar Schmidt, C., Michel, V., Miranda, M.A., Nielsen, S.S., Raj, M., Sihvonen, L., Spoolder, H., Stegeman, J.A., Thulke, H.-H., Velarde, A., Willeberg, P., Winckler, C., Baldinelli, F., Broglia, A., Candiani, D., Beltrán-Beck, B., Kohnle, L. and Bicout, D. 2017. Scientific opinion on the assessment of listing and categorisation of animal diseases within the framework of the Animal Health Law (Regulation (EU) No 2016/429): Border disease. EFSA J. 15(10), 4993.

Frei, S., Braun, U., Dennler, M., Hilbe, M., Stalder, H.P., Schweizer, M. and Nuss, K. 2014. Border disease in persistently infected calves: radiological and pathological findings. Vet. Rec. 174(7), 170.

Grattarola, C., Frey, J., Abdo, E.-M., Orusa, R., Nicolet, J. and Giacometti, M. 1999. Mycoplasma conjunctivae infections in chamois and ibexes affected with keratoconjunctivitis in the Italian alps. Vet. Rec. 145, 588-589.

Giangaspero, M. and Harasawa, R. 2007. Numerical taxonomy of genus Pestivirus based on palindromic nucleotide substitutions in the 5 , untranslated region. J. Virol. Methods 146, 375-388.

Giangaspero, M., Orusa, R., Nicholas, R.A.J., Harasawa, R., Ayling, R.D., Churchward, C.P., Whatmore, A., Bradley, D., Robetto, S., Sacchi, L. and Domenis, L. 2010. Characterization of mycoplasma isolated from an Ibex (Capra ibex) suffering from Keratoconjunctivitis in Northern Italy. J. Wildlife Dis. 46(4), 1070-1078.

Kumar, S., Stecher, G. and Tamura, K. 2016. MEGA7: molecular evolutionary genetics analysis version 7.0 for bigger datasets. Mol. Biol. Evol. 33, 18701874.

La Rocca, A. and Sandvik, T. 2009. A short target realtime RT-PCR assay for detection of pestiviruses infecting cattle. J. Virol. Methods, 161(1), 122-127.

Luzzago, C., Ebranati, E., Cabezon, O., FernandezSirera, L., Lavin, S., Rosell, R., Veo, C., Rossi,
L., Cavallero, S., Lanfranchi, P., Marco, I. and Zehender, G. 2016. Spatial and temporal phylogeny of border disease virus in Pyrenean Chamois (Rupicapra p. pyrenaica). PLoS One 11(12), e0168232.

Marco, I., López-Olvera, J.R., Rosell, R., Vidal, E., Hurtado, A., Juste, R., Pumarola, M. and Lavin, S. 2007. Severe outbreak of disease in the Southern chamois (Rupicapra pyrenaica) associated with border disease virus infection. Vet. Microbiol. 120, 33-41.

Martin, C., Duquesne, V., Adam, G., Belleau, E., Gauthier, D., Champion, J.L., Saegerman, C., Thiery, R. and Dubois, E. 2015. Pestiviruses infections at the wild and domestic ruminants interface in the French Southern Alps. Vet. Microbiol. 175(2-4), 341-348.

Martin, C., Duquesne, V., Guibert, J-M., Pulido, C., Gilot-Fromont, E., Gibert, P., Velarde, R., Thiéry, R., Marco, I. and Dubois, E. 2013. Experimental infection of pregnant Pyrenean chamois (Rupicapra pyrenaica) with border disease virus subtype 4 . J. Wildlife Dis. 49(1), 55-68.

Nettleton, P.F., Gilray, J.A., Russo, P. and Dlissi, E. 1998. Border disease of sheep and goats. Vet. Res. 29(3-4), 327-340.

Peletto, S., Caruso, C., Cerutti, F., Modesto, P., Zoppi, S., Dondo, A., Acutis, P.L. and Masoero, L. 2016. A new genotype of border disease virus with implications for molecular diagnostics. Arch. Virol. 161(2), 471-477.

Peterhans, E., Bachofen, C., Stalder, H. and Schweizer, M. 2010. Cytopathic bovine viral diarrhea viruses (BVDV): emerging pestiviruses doomed to extinction. Vet. Res. 41(6), 44.

Saitou, N. and Nei, M. 1987. The neighbor-joining method: a new method for reconstructing phylogenetic trees. Mol. Biol. Evol. 4, 406-425.

Storts, R.W. 1995. Central nervous system. In Special veterinary pathology. Eds., Carlton, W. and McGavin, M.D. $2^{\text {nd }}$ Edn., University Graphics Production Services, St. Louis, Missouri, pp: 372.

Strong, R., La Rocca, S.A., Ibata, G. and Sandvik, T. 2010. Antigenic and genetic characterisation of border disease viruses isolated from UK cattle. Vet. Microbiol. 141, 208-215.

Vilcek, S., Herring, A.J., Herring, J.A., Nettleton, P.F., Lowings, J.P. and Paton, D.J. 1994. Pestiviruses isolated from pigs, cattle and sheep can be allocated into at least three genogroups using polymerase chain reaction and restriction endonuclease analysis. Arch. Virol. 136, 309-323. 